\title{
PENGARUH CAHAYA TERHADAP TINGKAT KELANGSUNGAN HIDUP DAN PERTUMBUHAN KARANG LUNAK LOBOPHYTUM STRICTUM (OCTOCORALIA: ALCYONACEA) HASIL TRANSPLANTASI PADA SISTEM RESIRKULASI
}

\section{(THE EFFECT OF LIGHT ON SURVIVAL AND GROWTH RATE OF TRANSPLANTED SOFT CORAL LOBOPHYTUM STRICTUM (OCTOCORALIA: ALCYONACEA) IN RECIRCULATION SYSTEM)}

\author{
Beginer Subhan ${ }^{1,2}$, Dedi Soedharma ${ }^{2}$, Dondy Arafat ${ }^{3}$, Hawis Madduppa ${ }^{2}$, Fadillah Rahmawati ${ }^{2}$, Ayu \\ Ervinia $^{2}$, Aditya Bramandito ${ }^{3}$, Denny Khaerudi ${ }^{3}$, Ahmad Taufik Ghozali ${ }^{2}$ \\ ${ }^{1}$ Corresponding author \\ ${ }^{2}$ Laboratorium Biodiversitas dan Biosistematika Kelautan, Bagian Hidrobiologi Laut, Departemen Ilmu dan \\ Teknologi Kelautan, Fakultas Perikanan dan Ilmu Kelautan, Institut Pertanian Bogor, \\ E-mail: begi_ners@yahoo.com \\ ${ }^{3}$ Coraux (Scientific Diving Workshop), Fakultas Perikanan dan Ilmu Kelautan, Insitut Pertanian Bogor \\ Departemen Ilmu dan Teknologi Kelautan, Fakultas Perikanan dan Ilmu Kelautan, Institut Pertanian Bogor
}

\begin{abstract}
The current research was conducted to investigate the effect of light on growth of soft coral Lobophytum strictum. This species was transplanted and reared in two different ponds, uncovered pond (with light penetration) and covered pond (no light penetration. A total of 16 coral fragments was placed on each pond. Both, the survival rate and the growth rate were significantly different on the effect of light $(P<0.05)$. The soft coral on the uncovered pond was survive up to 12 weeks $(100 \%)$, followed with increased length (from 5,95 to 10,04 cm) and width (from 5,27 to 6,84 cm) of the transplanted coral fragments. Conversely, the soft coral in the covered ponds showed survival rate of 62,5\% (up to $8^{\text {th }}$ week), with decreased length (from 8,25 to 5,25 cm) and width (from 9,14 to 4,86 cm) of each fragments during the period of study.
\end{abstract}

Keywords: Coral transplantation, soft coral, survival rate, growth rate

\section{ABSTRAK}

Penelitian yang dilakukan untuk mengetahui pengaruh cahaya terhadap pertumbuhan karang lunak Lobophytum strictum hasil transplantasi dilakukan dengan pemeliharaan karang lunak pada dua buah kolam, yaitu kolam terbuka (cahaya) dan kolam tertutup (tanpa cahaya). Pada masing-masing kolam ditempatkan 16 fragmen karang lunak yang sudah ditransplantasikan. Kelangsungan hidup dan pertumbuhan karang lunak berbeda signifikan antar perlakuan cahaya $(\mathrm{P}<0,05)$. Karang lunak yang dipelihara di kolam terbuka mampu bertahan hidup 100\% (12 minggu), dengan disertai peningkatan panjang (5,95-10,04 cm) dan lebar (5,27-6,84 $\mathrm{cm}$ ) fragmen karang. Hal yang berbeda ditunjukkan karang lunak yang dipelihara di kolam tertutup, hanya mampu bertahan hidup hingga minggu ke-8 (62,5\%). Hal ini disertai dengan penurunan panjang $(8,25-5,25$ $\mathrm{cm})$ dan lebar $(9,14-4,86 \mathrm{~cm})$ fragmen setiap minggunya.

Kata kunci: Transplantasi karang, karang lunak, tingkat kelangsungan hidup, tingkat pertumbuhan

\section{PENDAHULUAN}

Karang lunak merupakan salah satu komponen pembentuk terumbu karang, pemasok senyawa karbonat, dan juga berkontribusi bagi keanekaragaman hayati lautan (Manuputty, 2002). Potensi dari karang lunak semakin tergali dengan perkembangan ilmu pengetahuan dan teknologi. Karang lunak berpotensi sebagai penghasil senyawa bioaktif yang berperan dalam penyedia bahan obatobatan (Soedharma \& Arafat, 2007), serta terdapat aktivitas antibakteri pada Lobophytum strictum (Triyulianti, 2009).

Kandungan senyawa aktif yang terdapat dalam karang lunak berpotensi mendorong dilakukannya eksploitasi karang lunak dari habitatnya, baik untuk kepentingan penelitian maupun kepentingan industrial. Salah satu upaya yang dapat dilakukan untuk dapat menjaga kelestarian dan pemenuhan bahan baku karang lunak adalah dengan transplantasi karang menggunakan fragmentasi buatan (Soedharma \& Arafat, 2007). Transplantasi karang lunak 
Lobophytum strictum juga telah dilakukan oleh Arafat et al., 2010.

Namun, upaya transplantasi ini sering menemui kendala, yaitu rendahnya tingkat kelangsungan hidup (Survival Rate) dan juga pertumbuhan yang lambat. Hal ini disebabkan karena adanya gangguan dari algae berfilamen serta ketidakmampuan karang beradaptasi pada kondisi lingkungan buatan. Faktor abiotik penting yang berpengaruh terhadap pertumbuhan karang adalah cahaya. Hal ini terkait dengan kelangsungan proses fotosintesis algae zooxanthellae yang terdapat di jaringan karang. Pada umumnya zooxanthellae ditemukan dalam jumlah besar dalam setiap polip, hidup bersimbiosis dengan karang lunak, memberikan warna pada polip, memberikan 90\% energi hasil fotosintesis kepada polip (Mannuputty, 1998). Oleh sebab itu, keberadaan cahaya sangat mempengaruhi kelangsungan hidup dan pertumbuhan karang.

Namun, di sisi lain keberadaan cahaya tidak hanya menstimulasi pertumbuhan dari algae zooxanthellae tetapi juga alga pengganggu lainnya. Keberadaan alga pengganggu dalam jumlah berlebihan dapat menghambat pertumbuhan karang karena algae menutupi permukaan tubuh karang (Haris, 2001). Oleh sebab itu, untuk mengetahui pengaruh cahaya terhadap kelangsungan hidup dan pertumbuhan karang lunak hasil transplantasi, dilakukan penelitian skala laboratorium dengan memelihara karang lunak hasil transplantasi pada dua jenis perlakuan, yaitu pada kolam terbuka (mendapat cahaya) dan kolam tertutup (tanpa cahaya). Hasil penelitian ini diharapkan dapat menjadi acuan bagi kegiatan transplantasi karang yang bermanfaat bagi pemulihan kawasan terumbu karang yang rusak.

\section{METODOLOGI PENELITIAN}

Karang lunak Lobophytum strictum bersumber dari Area Perlin-dungan Laut, Pulau Pramuka, Kepulauan Seribu. Karang lunak diambil dari koloni alami beserta substratnya, dengan ukuran panjang 25$30 \mathrm{~cm}$.

Karang lunak yang akan digunakan dalam penelitian adalah karang lunak hasil transplantasi. Namun, sebelum ditransplantasi, karang lunak diaklimasi pada kondisi kolam pemeliharaan selama 1 bulan. Penelitian dilakukan di Laboratorium Pusat Studi Ilmu Kelautan IPB, Ancol, Jakarta pada Juni 2010 hingga Januari 2011.

\subsection{Transplantasi Karang Lunak}

Koloni karang lunak dipotong menjadi 32 fragmen kecil secara vertikal (Okubo, 2004). Selanjutnya, potongan fragmen ditempelkan pada substrat buatan yang terbuat dari bahan semen dengan ukuran $20 \times 20 \mathrm{~cm}^{2}$. Sebelum digunakan, substrat dibersihkan terlebih dahulu dari organisme lain yang menempel.

\subsection{Rancangan Penelitian}

Sejumlah 32 fragmen karang lunak yang sudah ditransplantasi dipelihara pada dua jenis kolam perlakuan, yaitu kolam terbuka (mendapat cahaya) dan kolam tertutup (tanpa cahaya) dengan ukuran sebesar $3,5 \times 1,5 \times 1 \mathrm{~m}^{3}$. Pada masingmasing kolam terdapat 16 fragmen karang lunak. Karang lunak dipelihara selama 3 bulan (12 minggu).

Selama masa pemeliharaan, karang lunak diberi pakan alami berupa fitoplankton Chlorella sp. hasil kultur dari Lab. Mikroalga, ITK-IPB. Selain itu, diberikan pula liquidfry yang berguna untuk menstimulasi pertumbuhan fitoplankton.

\subsection{Pertumbuhan dan Kelangsungan Hidup}

Pertumbuhan karang lunak diketahui dengan mengamati panjang dan lebar fragmen karang lunak berdasarkan kapitulum terluar. Pengukuran panjang dan lebar dilakukan dengan menggunakan software Image $J 1,38 \mathrm{x}$ dari foto karang lunak, setiap satu kali seminggu (12 kali).

Tingkat kelangsungan hidup karang diketahui dengan mengamati karang lunak, hidup atau mati. Karang lunak hidup terlihat segar, berwarna cokelat kuning, dan fragmen tidak lembek. Berbeda dengan karang mati yang berwarna cokelat pucat, layu, dan fragmen akan hancur ketika dipegang.

Kualitas air kolam pemeliharaan diukur pada awal dan akhir pengamatan. Parameter kualitas air yang diukur adalah suhu, salinitas, nitrat, nitrit, dan amonia.

\subsection{Analisis Statistik}

Pengaruh perlakuan cahaya terhadap kelangsungan hidup dan pertumbuh- 
an karang lunak diketahui dengan melakukan analisis ragam dua arah (twoway ANOVA) pada taraf nyata $5 \%$.

\section{HASIL DAN PEMBAHASAN}

\subsection{Hasil}

Kelangsungan hidup karang lunak (Lobophytum strictum) berbeda signifikan antar perlakuan, yaitu antara karang yang dipelihara di kolam terbuka (cahaya) dan karang di kolam tertutup (tanpa cahaya). Rata-rata tingkat kelangsungan hidup pada karang di kolam terbuka sebesar $100 \%$ dan $87,5 \%$ pada kolam tertutup. Kolam yang dipelihara di kolam terbuka hanya bertahan hidup hingga minggu ke-8. Namun, tidak terdapat perbedaan signifikan kelangsungan hidup terhadap waktu pemeliharaan (Gambar 1, two-way ANOVA).

Pertumbuhan dari karang lunak digambarkan dengan penambahan ukuran panjang dan lebar dari fragmen karang dengan bertambahnya waktu. Terdapat perbedaan signifikan panjang dan lebar fragmen karang antar perlakuan cahaya (Gambar 2). Karang di kolam terbuka mengalami penambahan panjang dan lebar rata-rata, yaitu panjang $(5,95 \mathrm{~cm}$ menjadi $8,64 \mathrm{~cm})$ dan lebar $(5,27 \mathrm{~cm}$ menjadi 6,84 $\mathrm{cm}$ ) di akhir pemeliharaan (minggu ke-12). Sedangkan karang di kolam tertutup mengalami penurunan panjang dan lebar rata-rata, yaitu panjang $(8,25 \mathrm{~cm}$ menjadi $5,25 \mathrm{~cm})$ dan lebar $(9,14 \mathrm{~cm}$ menjadi 4,86 $\mathrm{cm}$ ) pada minggu ke-8, kemudian mati.

Laju pertumbuhan relatif karang lunak mengalami fluktuasi setiap minggunya. Terdapat perbedaan signifikan laju pertumbuhan panjang dan lebar karang antar perlakuan. Karang lunak yang dipelihara di kolam terbuka (cahaya) mengalami pertumbuhan panjang $(0,14-$ $1,25 \mathrm{~cm} /$ minggu) dan lebar $(0,50-1,37$ $\mathrm{cm} /$ minggu). Berbeda halnya dengan karang yang dipelihara di kolam tertutup. Karang mengalami pertumbuhan negatif berupa penurunan panjang $(0,09-1,92$ $\mathrm{cm} /$ minggu) dan lebar $(0,26-2,81$ $\mathrm{cm} /$ minggu).

Keberhasilan hidup dan tumbuh dari karang lunak hasil transpantasi juga dipengaruhi oleh kondisi kualitas kolam pemeliharaan. Secara umum, kualitas air pada kolam terbuka dan tertutup tidak berbeda signifikan. Kualitas air dinilai masih sesuai untuk mendukung kehidupan karang, terkecuali kandungan nutrien (nitrat) dan amonia yang melebihi batas maksimum kebutuhan hidup biota perairan (Tabel 1.). Kandungan nutrien meningkat di akhir waktu pemeliharaan.

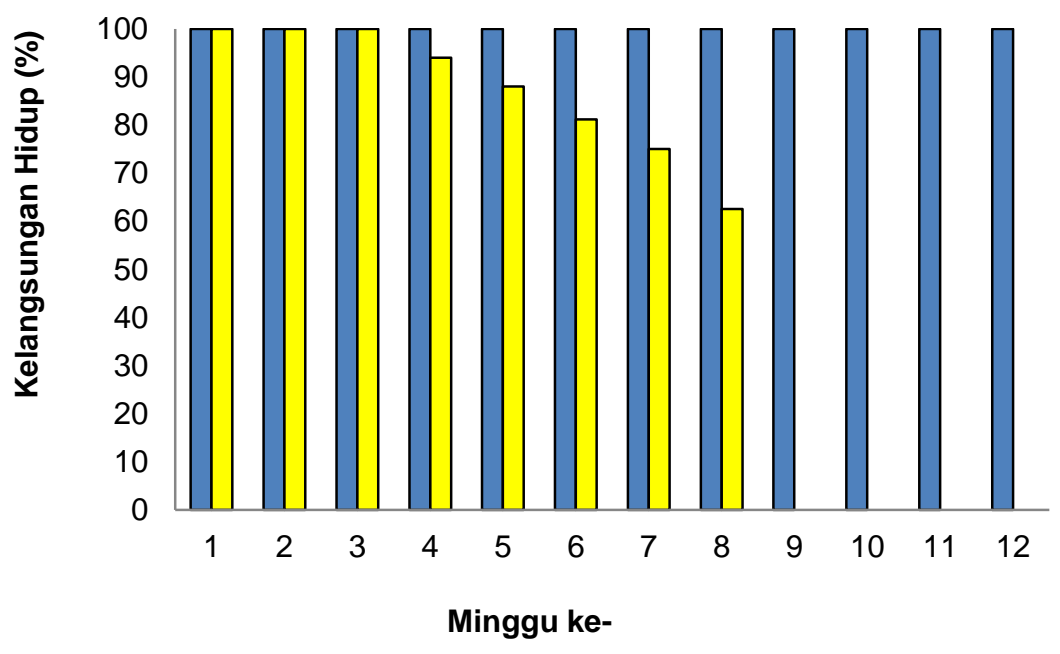

口cahaya $\quad$ tanpa cahaya

Gambar 1. Kelangsungan hidup karang lunak (Lobophytum strictum) yang dipelihara di kolam terbuka (cahaya) dan di kolam tertutup (tanpa cahaya) hingga minggu ke-12. Terdapat perbedaan signifikan $(\mathrm{P}=0,038, \mathrm{P}<0,05)$ kelangsungan hidup karang lunak antar perlakuan cahaya $(n=12)$ 

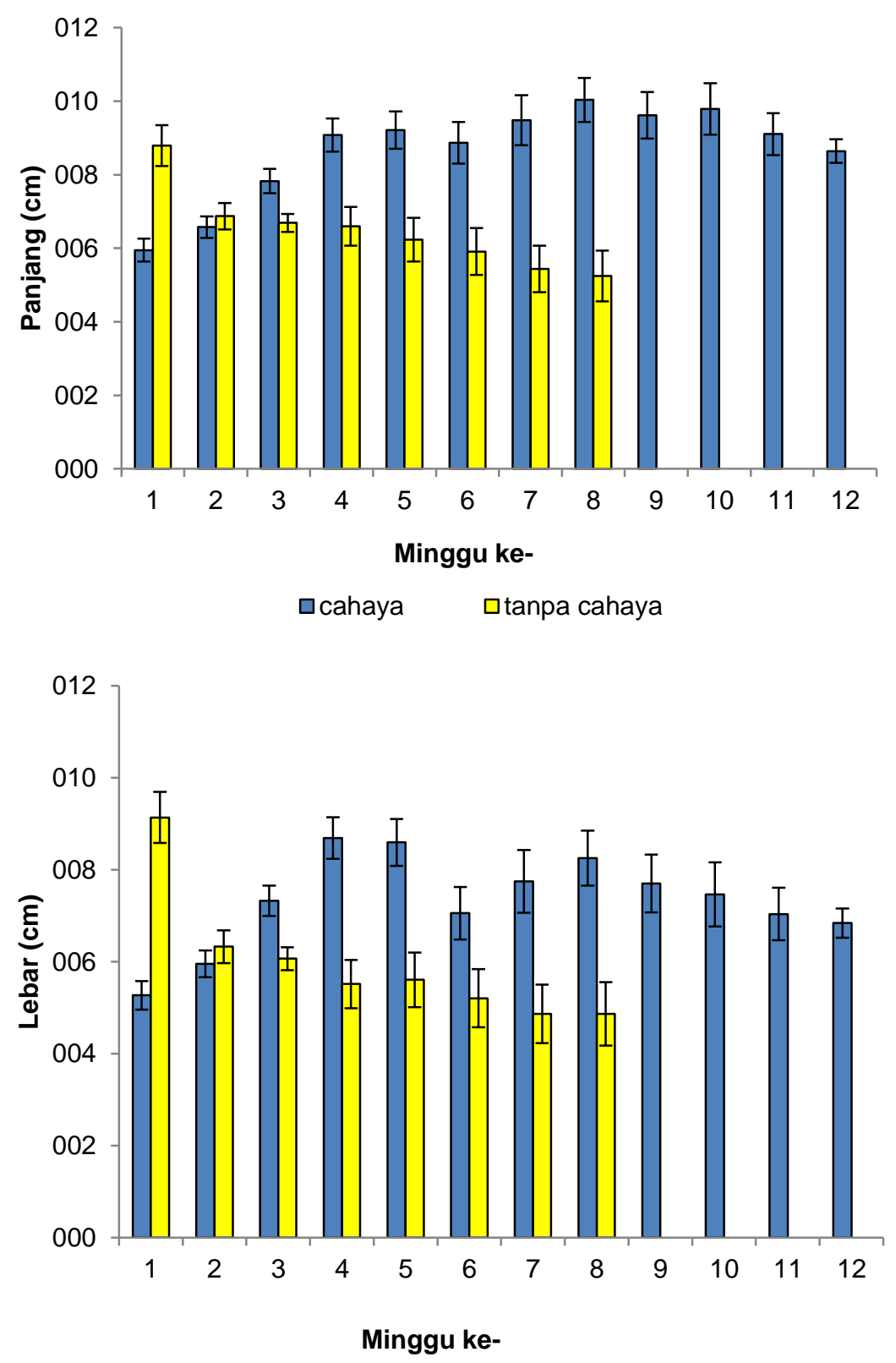

口cahaya $\quad$ tanpa cahaya

Gambar 2. Panjang dan lebar rata-rata karang lunak (Lobophytum strictum) yang dipelihara di kolam terbuka (cahaya) dan di kolam tertutup (tanpa cahaya) hingga minggu ke-12. Terdapat perbedaan signifikan (t-test, $\mathrm{P}<0,05$ ) panjang dan lebar rata-rata karang lunak antar perlakuan cahaya $\left(\mathrm{n}_{\text {cahaya }}=12\right.$ dan $\left.\mathrm{n}_{\text {tanpa cahaya }}=8\right)$ 

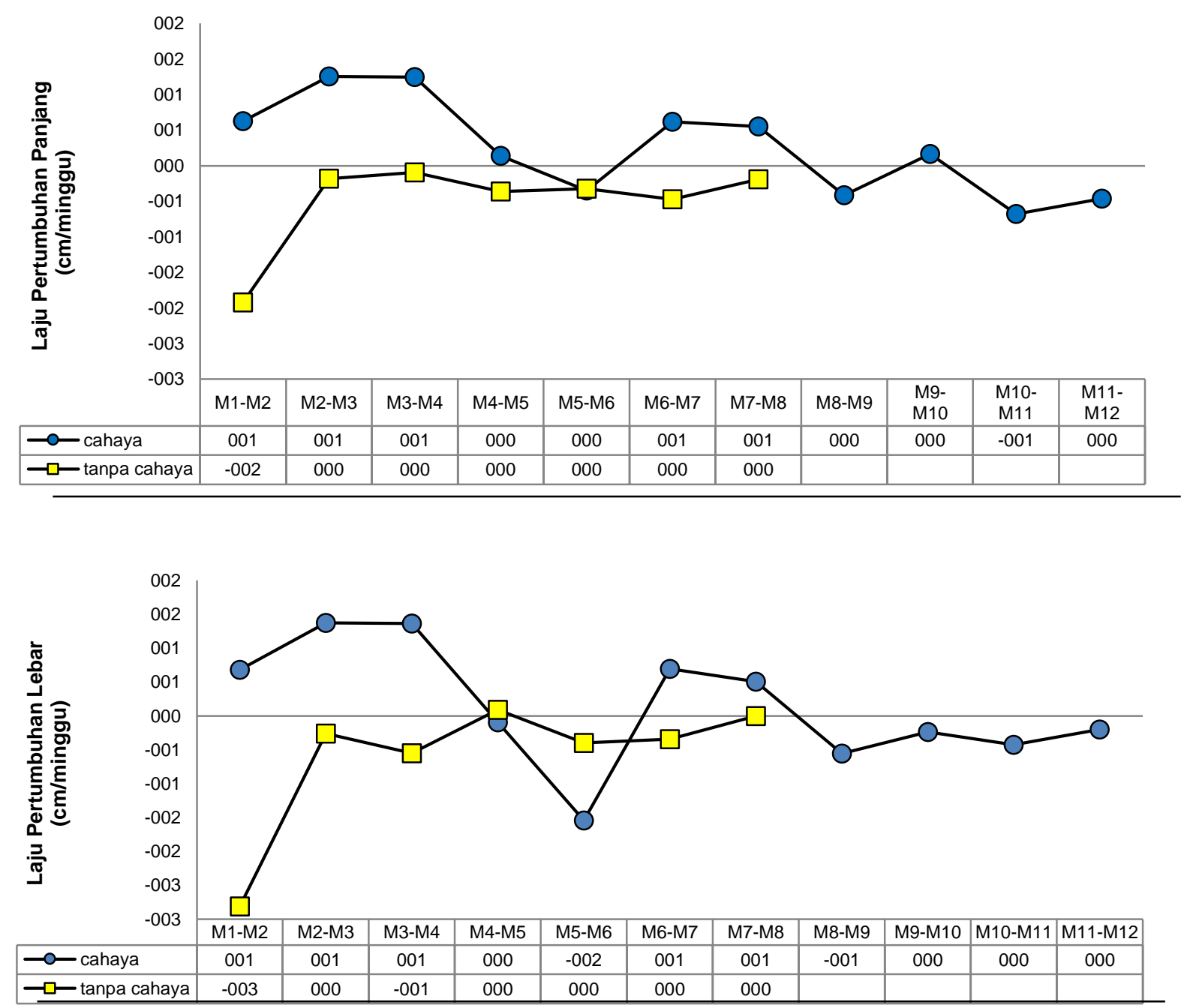

Gambar 3. Laju pertumbuhan relatif karang lunak (Lobophytum strictum) yang dipelihara di kolam terbuka (cahaya) dan di kolam tertutup (tanpa cahaya) hingga minggu ke-12. Terdapat perbedaan signifikan laju pertumbuhan panjang $(\mathrm{P}=0,0124, \mathrm{P}<0,05)$ dan laju pertumbuhan lebar $(\mathrm{P}=0,043, \mathrm{P}<0,05)$ antar perlakuan cahaya $(\mathrm{n}=7)$

Tabel 1. Kualitas air pada kolam pemeliharaan

\begin{tabular}{llllll}
\hline \multirow{2}{*}{ Parameter } & $\begin{array}{l}\text { Baku } \\
\text { Mutu } \\
(*)\end{array}$ & $\begin{array}{l}\text { Kolam } \\
\text { Terbuka }\end{array}$ & $\begin{array}{l}\text { Kolam } \\
\text { Tertutup }\end{array}$ \\
\cline { 3 - 6 } & $28-30$ & $26-28$ & & $(1)$ & $(2)$ \\
\hline Suhu $\left({ }^{\circ} \mathrm{C}\right)$ & $26-28$ & \\
Salinitas $(\%)$ & $33-34$ & $31-33$ & & $31-33$ & \\
Nitrat $(\mathrm{mg} / \mathrm{L})$ & 0,008 & 0,91 & 1,11 & 0,2 & 0,81 \\
Nitrit $(\mathrm{mg} / \mathrm{L})$ & & 0,002 & 0 & 0,001 & 0 \\
Amonia(mg/L) & 0,3 & 0,643 & 0,953 & 0,284 & 0,686 \\
\hline
\end{tabular}

*) Kep MEN LH No.51 tahun 2004 tentang Baku Mutu Kualitas Air untuk Biota

(1) awal pemeliharaan; (2) akhir pemeliharaan

\subsection{Pembahasan}

Penelitian ini menunjukkan bahwa keberadaan cahaya memberikan pengaruh signifikan terhadap kelang- sungan hidup dan pertumbuhan karang lunak Lobophytum strictum hasil transplantasi. Semua fragmen karang lunak yang dipelihara di kolam terbuka 
(cahaya) bertahan hidup hingga akhir penelitian. Berbeda dengan karang lunak yang dipelihara di kolam tertutup (tanpa cahaya), ketahanan hidup 100\% hanya berlangsung hingga minggu ke-3, selanjutnya mengalami penurunan hingga minggu ke-8.

Penurunan ketahanan hidup karang lunak dikarenakan karang mengalami stres akibat gagal melakukan adaptasi dengan kondisi lingkungan tanpa cahaya. Pada kondisi tersebut mikrosimbion karang, yaitu zooxanthellae akan keluar dari jaringan polip karang karena tidak mampu untuk berfotosintesis dalam kondisi gelap (Mannuputty, 1998). Keluarnya zooxanthellae dari tubuh karang dapat terlihat dari warna karang yang pucat kehilangan warna (Rani, 1999). Kehilangan zooxanthellae dalam waktu lama dapat menyebabkan bleaching dan akhirnya mematikan hewan tersebut (Glynn, 1993). Oleh karena itu, proses kematian karang dapat terdeteksi dengan adanya perubahan warna karang, yatu dari cokelat menjadi putih pucat (Suharsono, 1984).

Pertumbuhan panjang dan lebar rata-rata karang lunak pada kolam terbuka (cahaya) lebih baik dibanding karang lunak pada kolam tertutup (tanpa cahaya). Peningkatan panjang dan lebar sangat nampak pada karang lunak di kolam terbuka Hal sebaliknya pada karang lunak di kolam tertutup, yaitu panjang dan lebar karang terus mengalami penurunan setiap minggunya (Gambar 2). Peranan cahaya bagi pertumbuhan karang terkait dengan kehidupan mikrosimbion zooxanthellae yang hidup dalam polip karang. Hampir 90\% makanan karang bersumber dari produk fotosintesis zooxanthellae (Veron in Zulfikar, 2003), sehingga dalam kondisi gelap akan terjadi hambatan fotosintensis. Hal ini berimbas pada kurangnya pasokan makanan bagi pertumbuhan karang lunak di kolam tertutup.

Laju pertumbuhan karang lunak yang negatif pada kolam tertutup ternyata tidak hanya dipengaruhi oleh kurangnya makanan. Dalam penelitian ini, karang lunak sudah diberi pakan tambahan berupa Chlorella sp. Namun upaya tersebut tetap tidak dapat menggantikan peran dari mikrosimbion karang. Zooxanthellae tidak hanya berperan dalam memberikan asupan makanan kepada karang, tetapi juga membantu dalam proses kalsifikasi (pembentukan rangka kalsium karbonat). Hal ini ditunjukkan dengan kemampuan karang dalam menyerap kalsium yang optimal pada siang hari hingga sore hari dibanding pada malam hari (Horani et al., 2007). Pengkerutan, penyusutan tubuh, dan pengeluaran lendir dinilai sebagai daya adaptasi karang untuk bertahan hidup dalam kondisi lingkungan yang kurang baik bagi pertumbuhannya (Zulfikar, 2003).

Kondisi lingkungan yang sesuai bagi pertumbuhan karang tergambar di kolam terbuka, yaitu terdapat cahaya matahari dan nutrien yang dibutuhkan zooxanthellae untuk fotosintesis. Selanjutnya hasil fotosintesis ini menjadi input bagi pertumbuhan karang. Hal ini ditunjukkan dengan peningkatan laju pertumbuhan karang lunak hingga minggu ke-8. Kemudian mulai terjadi penurunan laju pertumbuhan, yang ditandai dengan penurunan panjang dan lebar fragmen karang.

Sama halnya dengan karang di kolam tertutup, karang di kolam terbuka juga diberi pakan tambahan berupa Chlorella sp. Namun dalam kondisi cahaya tersedia, zooxanthellae masih dapat optimal melakukan fotosintesis sehingga pasokan makanan bagi karang dipenuhi dari hasil fotosintesis tersebut. Hal ini menyebabkan banyak Chlorella sp. yang tidak dimakan oleh karang lunak dan menjadi sumber keberadaan bahan organik di perairan. Bahan organik ini selanjutnya akan mengalami proses dekomposisi dan mineralisasi menjadi nutrien.

Keberadaan nutrien dalam jumlah berlebihan akan menstimulasi kehadiran dan pertumbuhan alga kompetitor di perairan (Nybakken, 2000). Alga berfilamen ini akan mengganggu efektivitas pemanfaatan cahaya oleh zooxanthellae karena ia dapat tumbuh di permukaan fragmen karang, serta mampu memotong jaringan tubuh karang lunak yang ditransplantasikan. Pertumbuhan alga yang pesat dan menutupi permukaan polip karang, menghalangi zooxanthellae berfotosintesis. Akibatnya, karang lunak di kolam terbuka (cahaya) mengalami penurunan laju pertumbuhan di waktu akhir pemeliharaan (Gambar 3). 
Selain itu, pada waktu tersebut terjadi curah hujan yang cukup tinggi sehingga kolam mendapat penambahan air tawar sehingga terjadi penurunan salinitas (Rachmawati, 2001). Salah satu cara adaptasi yang dapat dilakukan adalah dengan menarik tentakel dari polip ke dalam rongga tubuh dan menyusutkan massa tubuh mereka hingga sepertiga dari ukuran panjang dengan mengeluarkan air (Ellis \& Sharron, 1999).

\section{DAFTAR PUSTAKA}

Arafat D., NP Zamani, A Winarto, D Soedharma, M Kawaroe, H Effendi, B. Subhan. 2010. Soft Coral Growth (Octocorallia : Alcyonacea) Lobophytum strictum and Sinularia dura As a Result Fragmentation in Pramuka Island, Seribu Island, Jakarta. Proceeding of Coral Reef Management Symposium on Coral Triangle Area. (eds) Jamaludin Jompa, Riyanto Basuki, Suraji, Mike Teroso, Eva Tri Lestari. COREMAP II, Directorate General of Marine, Coasts and Small Island. Ministry of Marine Affairs and Fisheries : $101-109$.

Ellis E \& L Sharon. 2005. The culture of soft corals (Order: Alcyonacea) for the marine aquarium trade. Center for tropical and subtropical aquaculture publication. $137 \mathrm{p}$.

Glynn PW. 1993. Coral reef bleaching. Ecological perspective. Coral reefs (1993) 12: 1-17.

Haris A. 2001. Laju pertumbuhan dan tingkat kelangsungan hidup fragmentasi buatan karang lunak (Octocorallia: Alcyonacea) Sarchophyton trocheliophorum Von Marenzeller dan Lobophytum strictum Tixier-Durivault di perairan Pulau Pari, Kepulauan Seribu. [Tesis] tidak dipublikasikan. Program Pascasarjana. Institut Pertanian Bogor. Bogor.

Keputusan Menteri Negara Lingkungan Hidup No.51 Tahun 2004 Tentang Baku Mutu Air laut untuk Biota Laut.
Manuputty AEW. 1998. Beberapa karang lunak (Alyonecea) penghasil substansi bioaktif. Seminar potensi farmasitik dan bioaktif sumberdaya hayati terumbu karang. Puslitbang-Oseanologi. Lembaga Ilmu Pengetahuan Indonesia. Jakarta.

Nybakken JW. 2000. Biologi laut, suatu pendekatan ekologi. Diterjemahkan oleh HM. Eidman, Koesoebionom, DG. Bengen, M.Hutomo, dan S.Sukarjo. PT. Gramedia. Jakarta. 459 hlm.

Okubo N, H. Taniguchi, \& T. Motokawa. 2005. Successful methods for transplanting fragmen of Acropora formosa and Acropora hyacinthus. Coral Reef. Lembaga Ilmu Pengetahuan Indonesia. Jakarta. 24: 333-342.

Rachmawati R. 2001. Terumbu buatan (artificial reef). Pusat Riset Teknologi Kelautan. Badan Riset Kelautan dan Perikanan. Departemen Kelautan dan Perikanan. Jakarta.

Rani C. 1999. Respon pertumbuhan karang batu Pocilopora verrucosa Ellis\&Solander dan kepiting Trapezia ferrugenia Latreile, xanthidae (yang hidup bersimbiosis) pada beberapa karakteristik habitat. [Tesis] Institut Pertanian Bogor. Bogor.

Soedharma D \& D Arafat. 2007. Perkembangan transplantasi karang di Indonesia, hlm 1-7. Prosiding Seminar Transplantasi Karang. Bogor, 8 September 2005. Pusat Pengkajian Lingkungan Hidup Institut Pertanian Bogor. Bogor.

Suharsono. 1984. Pertumbuhan karang. Oseana. Puslitbang-Oseanologi. Lembaga Ilmu Pengetahuan Indonesia. Jakarta. 9:41-48.

Triyulianti I. 2009. Bioaktivitas ektrak karang lunak Sinularia sp. dan Lobophytum sp. hasil fragmentasi di perairan Pulau Pramuka, Kepulauan Seribu, DKI Jakarta. [Tesis] tidak dipublikasikan. Program Pascasarjana. Institut Pertanian Bogor. Bogor. 
Zulfikar. 2003. Pertumbuhan dan kelangsungan hidup karang (Caulastrea furcata dan Cynarina lacrimaris) hasil fragmentasi buatan pada kondisi terkontrol. [Tesis] tidak dipublikasikan. Program Pascasarjana. Institut Pertanian Bogor. Bogor. 